\title{
Microstructure and mechanical properties of aluminium-graphene composite powders produced by mechanical milling
}

\author{
Jiangshan Zhang, Zhixin Chen, Jingwei Zhao and Zhengyi Jiang*
}

\begin{abstract}
Background: Graphene has been reported to be a promising nanofiller in fabricating advanced metal matrix composites.

Methods: Graphene nanosheets (GNSs) have been incorporated into an aluminium matrix composite using mechanical milling and hot pressing in the current study.

Results: The SEM observation shows that aluminium particles are firstly flattened into flakes, and then fractured/ rewelded into equiaxed particles as the ball milling progresses. The crystalline size is decreased and the lattice strain is increased during the ball milling, which are also intensified by the added GNSs. The hardness of the composite is increased by $115.1 \%$ with the incorporation of 1.0 vol. \% GNSs.

Conclusions: The local stress induced by the hard GNSs accelerates the milling process. The X-Ray diffraction patterns show that the intensity ratio of (111) to (200) can reflect the preferred orientation of the particle mixture, and the evolution of I(111)/I(200) agrees well with the observed results using SEM. The increased hardness is mainly attributed to the refined microstructure and Orowan strengthening.
\end{abstract}

Keywords: Aluminium matrix composite, Mechanical milling, Graphene, Microstructure

\section{Introduction}

Aluminium matrix composite (AMC) has found wide application in the fields of aerospace, automobile, military, transportation and building, due to its attractive properties such as light weight, corrosion resistance and superior ductility (Bodunrin et al. 2015). Graphene is a very promising reinforcing phase in AMC because of its outstanding properties, including high mechanical strength, modulus, thermal and electrical conductivity (Stankovich et al. 2006; Novoselov et al. 2012; Zhu et al. 2010; Niteesh Kumar et al. 2017; Shin et al. 2015). Bartolucci et al. (2011) are among the pioneer researchers and introduced graphene into AMCs using ball milling in 2011. Graphene is normally added into the matrix in the form of graphene nanosheets (GNSs) with several to tens of layers (Asgharzadeh and Sedigh 2017; Pérez-Bustamante et al. 2014; Nieto et al. 2016). Up to 5 wt.\% GNSs were incorporated into AA2124

\footnotetext{
* Correspondence: jiang@uow.edu.au

School of Mechanical, Materials, Mechatronic and Biomedical Engineering, University of Wollongong, Wollongong, NSW 2522, Australia
}

alloy, and it was found that the hardness of the composite was increased by $102 \%$; the wear rate decreased $25 \%$ with 9\% reduction in coefficient of friction (El-Ghazaly et al. 2017). A wet method was utilised to mix aluminium with graphene in the study of Asgharzadeh et al. (2017), which showed that the yield strength and hardness were both enhanced. The possible strengthening mechanism for the GNSs reinforced AMCs were reported to be grain refinement, Orowan strengthening, stress/load transfer and increased dislocation density (Nieto et al. 2016). The strengthening effect of GNSs also highly depends on the uniform dispersion of GNSs among the metal grains. Mechanical milling involves the cold welding, fracturing and rewelding of particles, which is an effect way to uniformly disperse GNSs into aluminium matrix (Nieto et al. 2016; Hu et al. 2016; Suryanarayana and Al-Aqeeli 2013). In the literature, it is noted that Al-Si alloy is widely used in the fields of aerospace and automobile due to its high specific strength, good corrosion resistance and castability (Mazahery and Shabani 2012). However, this alloy is 
restricted in certain tribological applications owing to the low hardness and wear-resistance. GNSs are in the right place to improve the hardness and tribological behaviour, as GNSs are potential to boost the mechanical properties and are also tribology-favoured (Nieto et al. 2016).

The research on GNSs reinforced Al-Si alloy is still quite limited. The current study focuses on the synthesis and characterisation of GNSs reinforced A355 Al-Si alloy matrix composites. The effect of GNSs on the morphological and microstructural evolution of the composite powder has been investigated during the mechanical milling. The preferred orientation, lattice strain, crystalline size and micro hardness have been studied as well.

\section{Experimental}

\section{Starting materials}

The morphologies of the starting materials are shown in Fig. 1. The as-received aluminium powder is generally in spherical shape. Commercial A355 Al-Si alloy (Si: 4.6\%, Cu: 0.8\%, Mg: $0.51 \%$ and Fe: $0.15 \%)$ powder with an average particle size of $30 \mu \mathrm{m}$ was supplied by Haoxi Nanotechnology. The GNSs are characterised with 1-5 $\mathrm{nm}$ in thickness and $\sim 5.0 \mu \mathrm{m}$ in lateral size, which were bought from XFNANO Materials Tech. as shown in Fig. 1(b) and (c).

\section{Ball milling}

The powder mixture of $\mathrm{Al}$ alloy and 1.0 vol.\% GNSs was milled in a planetary ball mill, which was carried out in a $500 \mathrm{ml}$ stainless steel jar. The confined powders were firstly ball milled at $180 \mathrm{rpm}$ for $0.5 \mathrm{~h}$ for pre-mixing, and then at $250 \mathrm{rpm}$ for the following $20 \mathrm{~h}$ under argon atmosphere. Samples were taken out at 2, 5, 10, 15 and $20 \mathrm{~h}$ to investigate the effect of ball milling on the microstructure of the powder mixture. In a typical milling campaign, $300 \mathrm{~g}$ of $5 \mathrm{~mm}$ stainless steel balls was used with a ball to powder ratio of $15: 1$ in mass. Stearic acid (2 wt.\%) flakes were added to work as a process control agent. To avoid the overheating and sticking of the powder mixture, every $5 \mathrm{~min}$ ball milling was followed with15 min rest in every milling cycle. Pure A355 powder was ball milled under the same conditions for reference.

\section{Morphological and microstructural evolution of the powder mixture}

The ball milled powders at different times were observed on the JEOL JSM-7500FA microscope with an acceleration voltage of $5 \mathrm{kV}$. X-Ray diffraction (XRD) patterns were acquired using GBC MMA XRD diffractometer with $\mathrm{Cu}-\mathrm{K} \alpha$ radiation from $25^{\circ}$ to $85^{\circ}$. The step size and
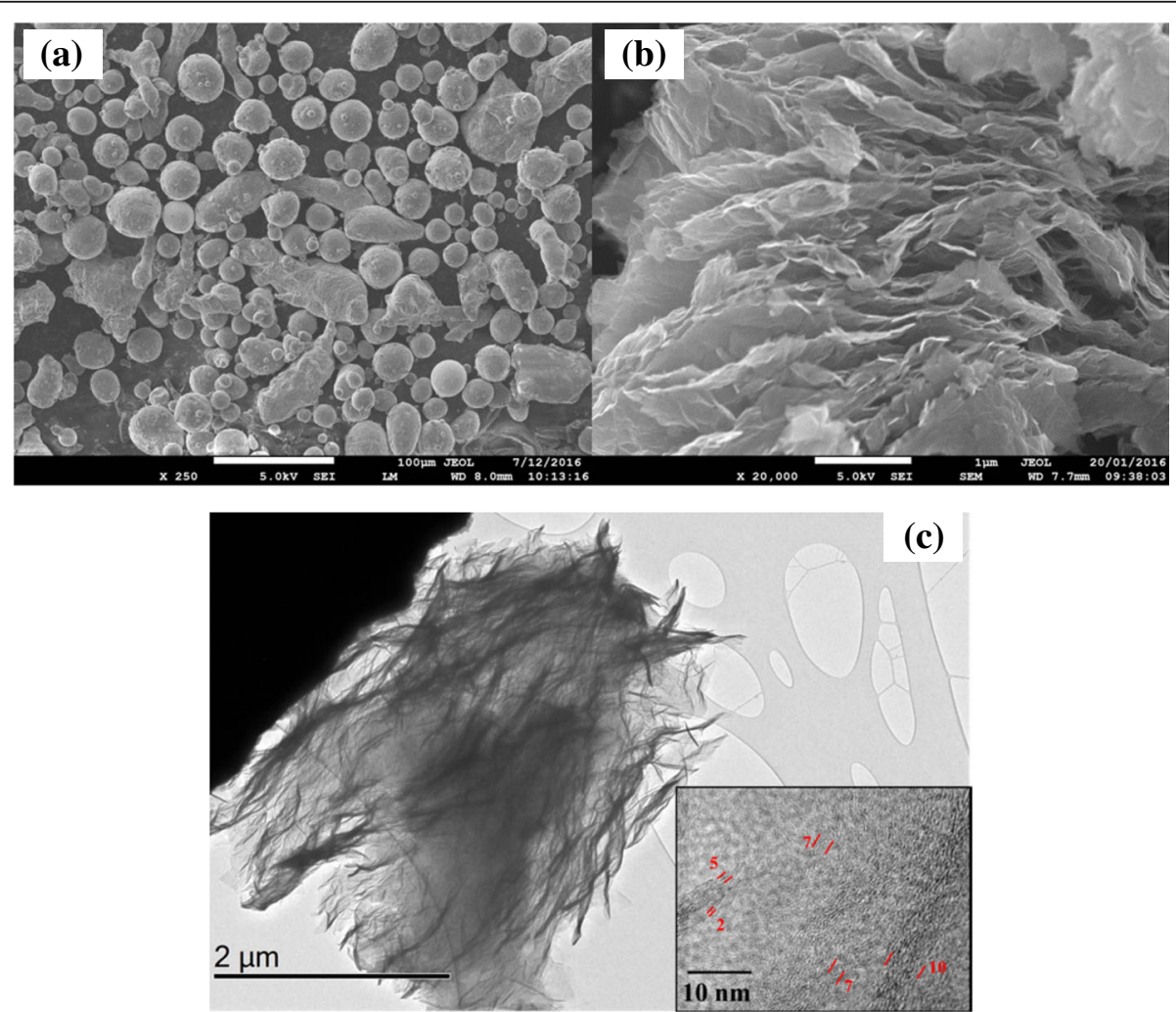

Fig. 1 The SEM morphologies of the as-received (a) aluminium powder. The morphology of the as-received GNSs observed using (b) SEM and (c) TEM. The inset shows a high-resolution micrograph of the lattice of the GNSs, with indicated number of layers 
scanning rate were $0.02^{\circ}$ and $1.5 \% \mathrm{~min}$ respectively. The crystalline size and lattice strain were analysed using William-Hall theory as follows (Wagih 2014):

$$
B \cos \theta=\frac{0.9 \lambda}{D}+4 \varepsilon \sin \theta
$$

where $B, \lambda, \theta, D$ and $\varepsilon$ are the full width half maximum, the wave length of X-ray, the peak positions, crystalline size and lattice strain of the powder, respectively.

\section{Fabrication and characterisation of the bulk materials}

The ball milled powders were cold pressed at $350 \mathrm{MPa}$ and then vacuum hot pressed under $50 \mathrm{MPa}$ at $500{ }^{\circ} \mathrm{C}$ for $60 \mathrm{~min}$ to produce $\Phi 20 \mathrm{~mm}$ disks. The disks were degasified to remove the stearic acid at $400{ }^{\circ} \mathrm{C}$ for $2 \mathrm{~h}$ before the hot pressing. The produced disks were grinded using abrasive papers and polished before the following characterisation. Vickers hardness was measured on a TIME TH715 micro-hardness tester under $9.8 \mathrm{~N}$ with a dwell time of $10 \mathrm{~s}$. At least ten readings were taken for each sample to obtain the average value. Raman tests were conducted on a WITec alpha 300R confocal Raman microscope (532 $\mathrm{nm}$ laser) to examine the distribution of GNSs. TEM samples were prepared using a FEI Helios nanoLab G3 CX dual beam microscope and then observed on a JEOL JEM-2011microscope.

\section{Results and discussion Morphology}

The SEM micrographs of the ball milled $\mathrm{Al}$ alloy and Al-GNSs composite powders are shown in Figs. 2 and 3 respectively. Aluminium is a relatively ductile phase in the ball milling system, while $\mathrm{Si}$ and GNSs particles are relatively brittle. The ductile aluminium particles are repeatedly flattened, cold welded, fractured and rewelded in the ball milling process (Suryanarayana and Al-Aqeeli 2013). As shown in Fig. 2, the starting aluminium particles are in spherical shape with about $\Phi 30 \mu \mathrm{m}$ in diameter and gradually flatten into flakes from 2 to $10 \mathrm{~h}$. The lateral size of the aluminium flakes reaches around $80 \mu \mathrm{m}$ at $10 \mathrm{~h}$. The flakes are fractured into smaller pieces at $15 \mathrm{~h}$ as shown in Fig. 2(e) and rewelded into equiaxed particles at $20 \mathrm{~h}$. The relatively hard phase, $\mathrm{Si}$, could accelerate the fracturing and rewelding, and is embedded into the aluminium matrix (Suryanarayana and Al-Aqeeli 2013). The presence of GNSs can further intensify the localised stress, and thus accelerates the flattening of aluminium powders as shown

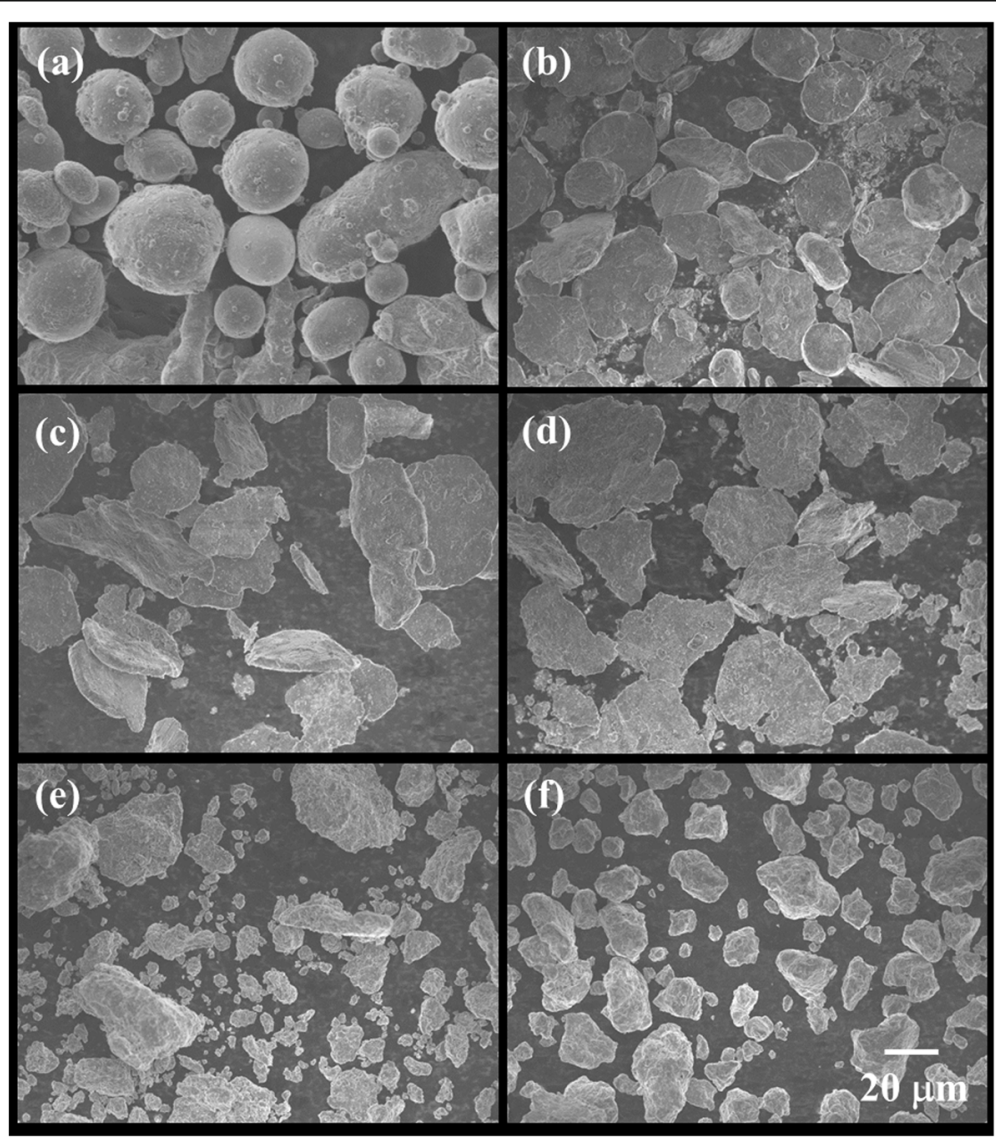

Fig. 2 The SEM morphologies of the ball milled Al alloy powders at (a) 0 h, (b) 2 h, (c) 5 h, (d) 10 h, (e) 15 h and (f) $20 \mathrm{~h}$ 


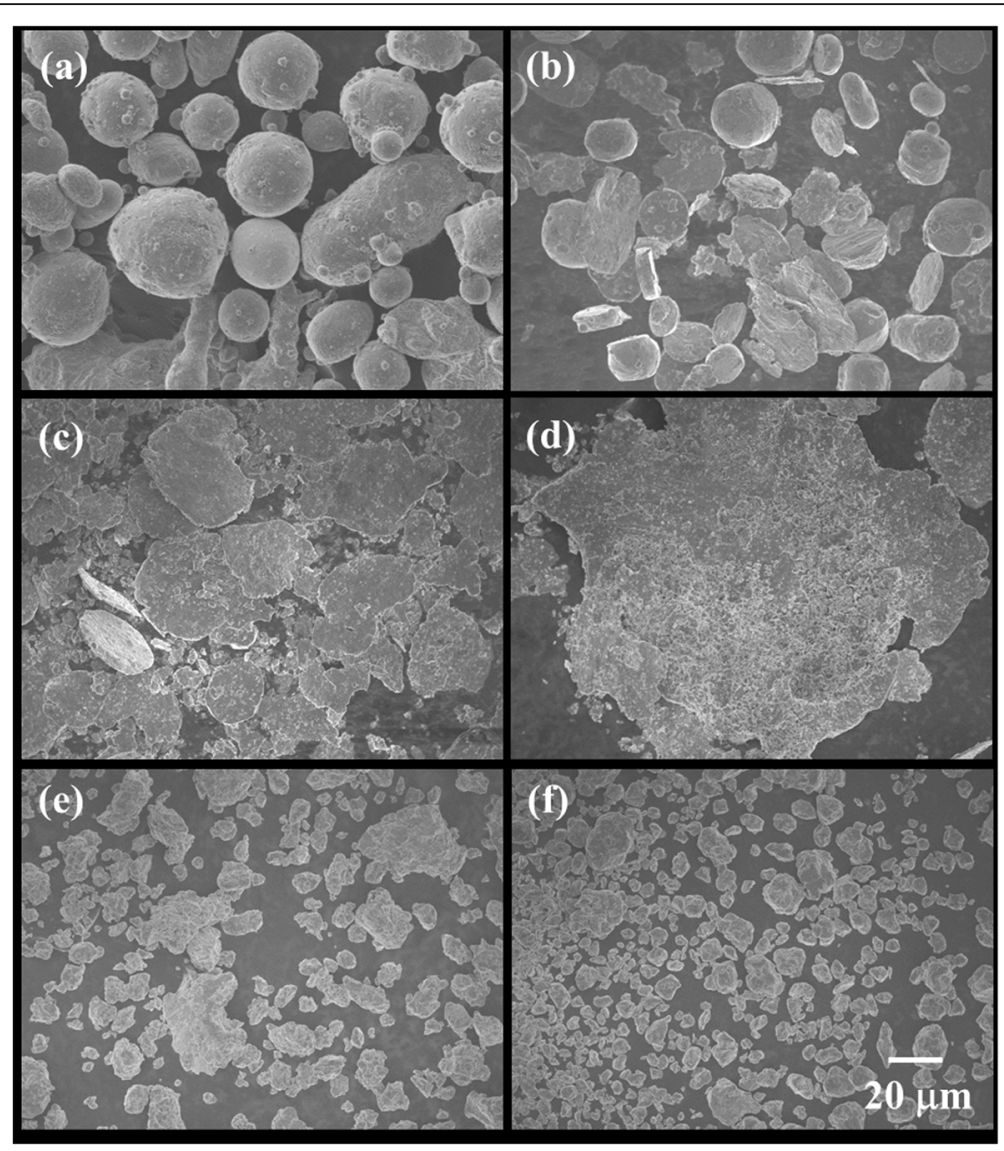

Fig. 3 The SEM morphologies of the ball milled Al-GNSs composite powders at (a) 0 h, (b) 2 h, (c) 5 h, (d) 10 h, (e) 15 h and (f) $20 \mathrm{~h}$

in Fig. 3 (a) to (d). Aluminium flakes with more than $120 \mu \mathrm{m}$ in lateral size can been seen at $10 \mathrm{~h}$. When the plastically deformed aluminium flakes are work-hardened to a critical level, the localized stress induced by GNSs will promote the fracture and rewelding of powders. As shown in Fig. 3 (e) to (f), aluminium powders are fractured and rewelded into relatively equiaxed shape at $15 \mathrm{~h}$ and further fractured into smaller particles at $20 \mathrm{~h}$. As a result, the size of the Al-GNSs mixture is less than $20 \mu \mathrm{m}$, which is smaller than the size of the $\mathrm{Al}$ alloy powder (around $25 \mu \mathrm{m})$ after $20 \mathrm{~h}$ of ball milling. The GNSs tend to become occluded and trapped in the aluminium particles, and finally get uniformly dispersed inside the matrix (Suryanarayana and Al-Aqeeli 2013).

\section{Microstructural analysis}

The XRD patterns of the ball milled $\mathrm{Al}$ alloy and Al-GNSs powder mixtures at different milling times are shown in Figs. 4 and 5 respectively, revealing the microstructural evolution of the powder mixing during the ball milling. It is seen that the peak intensity of aluminium decreases with the increase of milling times up to $20 \mathrm{~h}$. There is no obvious change for the peaks of $\mathrm{Si}$, indicating no significant structural change for this relatively hard phase. As the concentration of GNSs is only $1.0 \mathrm{vol} . \%$, the peak of GNSs is not distinguishable in XRD observation. For FCC metals, it has been indicated that the intensity ratio of (111) to (200), I(111)/ $\mathrm{I}(200)$, can reflect the change in crystallographic orientation of particles in the ball milling process. While for BCC metals, I(110)/ I(200) is used (Razavi-Tousi and Szpunar 2015; Alizadeh et al. 2011). As shown in Fig. 6, the $\mathrm{I}(111) / \mathrm{I}(200)$ firstly drops to a minimum value and then increases to the initial level. This process is faster for the Al-GNSs composite due to the aforementioned localised stress induced by the addition of GNSs. This could be explained by considering the anisotropy in the elastic modulus of a single aluminium crystal (Alizadeh et al. 2011). To be specific, the aluminium grains/particles tend to be deformed in the soft direction (111), which is perpendicular to the collision direction of milling balls. When the powder sample is prepared for the XRD analysis, the flattened flakes arrange themselves parallel to the sample holder. As a result, I(111) decreases and $I(200)$ increases, which is the case for the powders from 2 to $10 \mathrm{~h}$. With further ball milling, the flattened particles are fractured and rewelded into equiaxed particles, which means the texture and the 


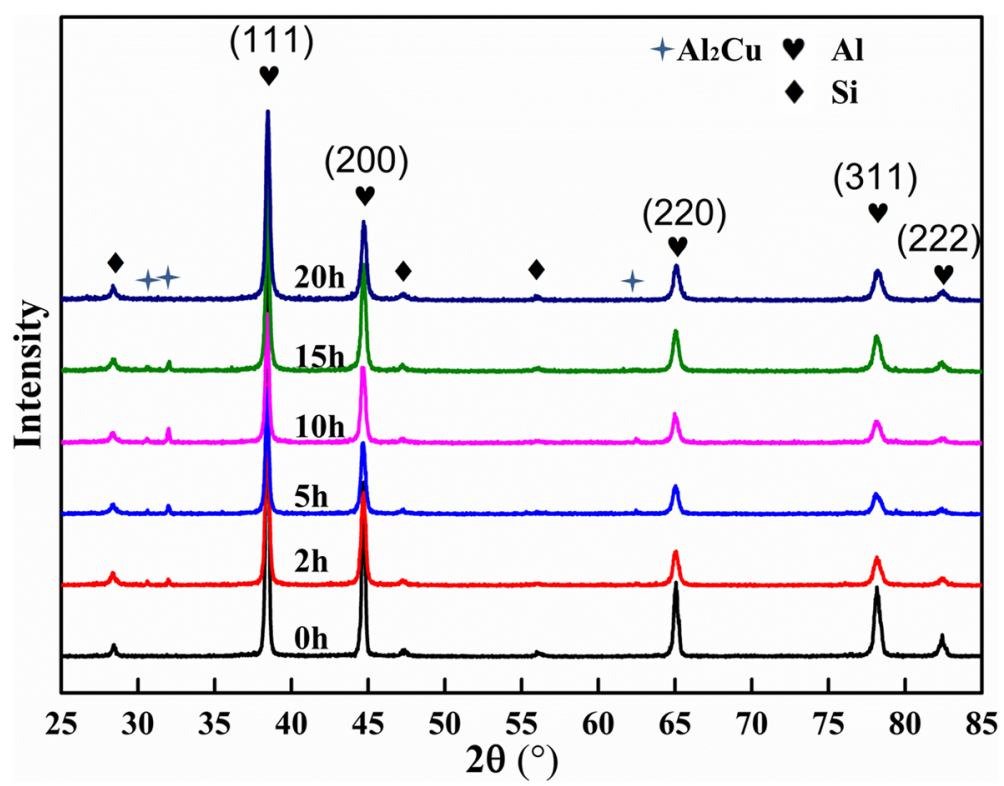

Fig. 4 The XRD patterns of the ball milled Al alloy powders at different times

preferential orientation are eliminated from 15 to $20 \mathrm{~h}$. Meanwhile, the $\mathrm{I}(111) / \mathrm{I}(200)$ recovers to the initial level. This evolution behaviour agrees very well with the SEM observation results as shown in Figs. 2 and 3, which show the morphological change of the powders.

It is also seen in Figs. 4 and 5 that peak broadening is caused as the milling process progresses, which indicates the refinement of crystalline grains and the generation of lattice strain. The mean crystalline size and lattice strain can be evaluated using the William-Hall theory, and are illustrated versus milling time in Figs. 7 and 8 respectively. It is shown in Fig. 7 that the crystalline size of aluminium decreases quickly during the initial $5 \mathrm{~h}$ and decrease slowly in the following milling process. In addition, the crystalline size of Al-GNSs composite is smaller than that of $\mathrm{Al}$ alloy at the same milling time, which could be attributed to the intensified stresses by the GNSs. This also causes the increased lattice strain during the ball milling as shown in Fig. 8. The GNSs

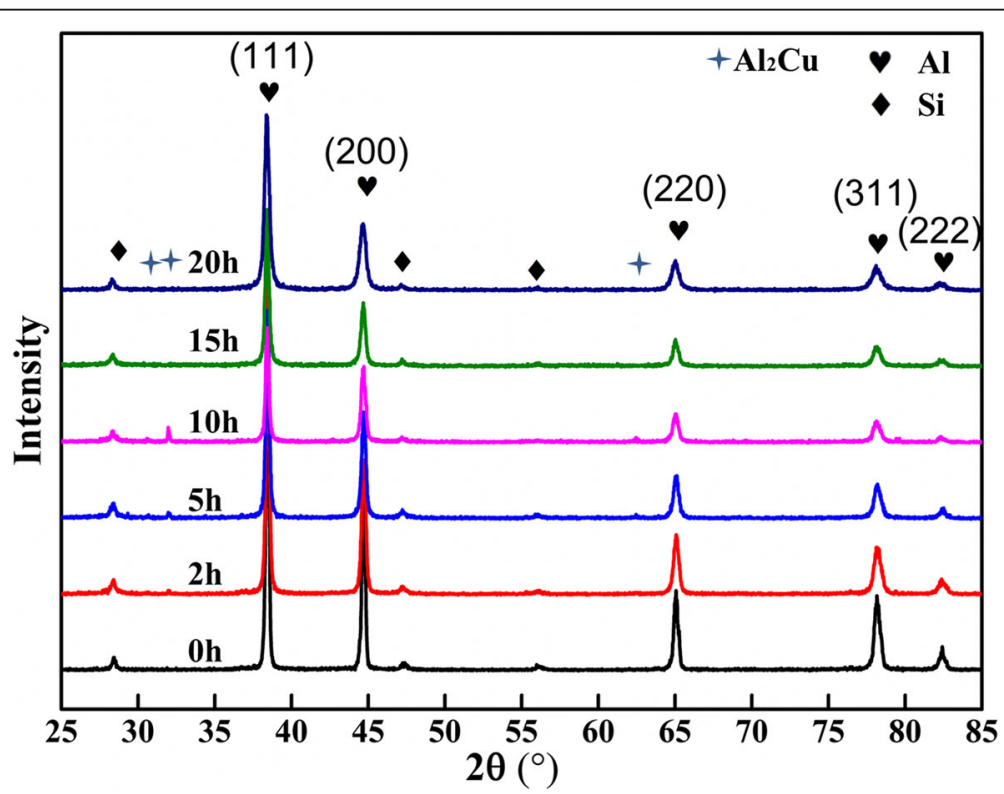

Fig. 5 X-Ray diffraction patterns of the ball milled Al-GNSs composite powders at different times 


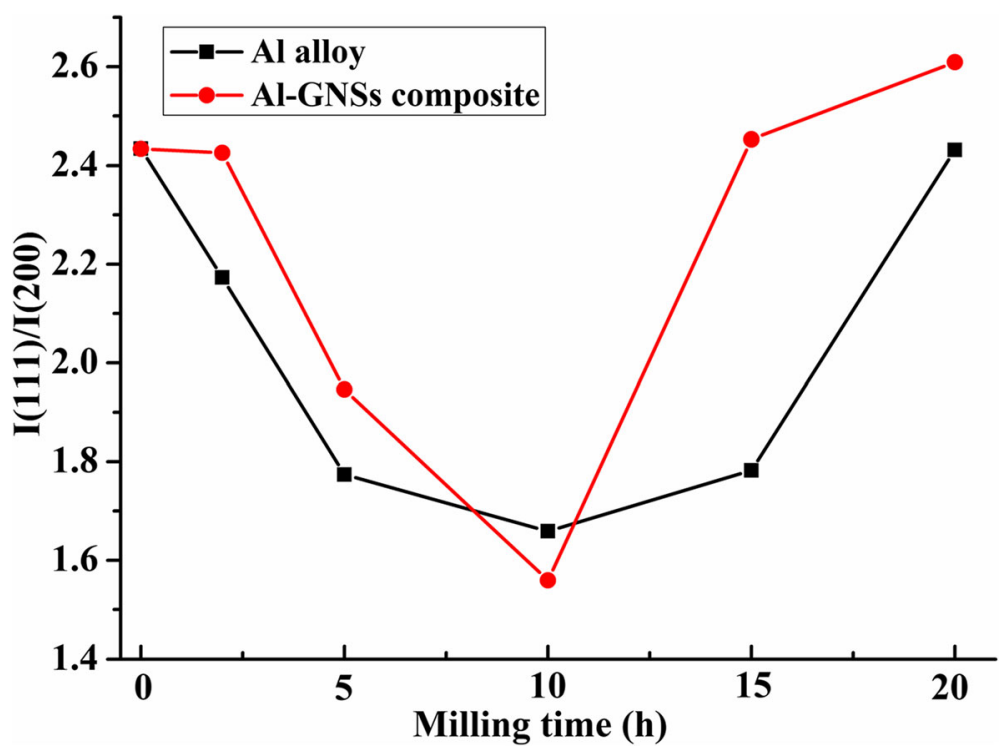

Fig. 6 The intensity ratio of (111) to (200) at different milling times

accelerate the deformation of the crystalline lattice and promote the lattice strain rate of Al-GNSs composite.

Figure 9 shows the TEM microstructure of the produced bulk samples. For the $\mathrm{Al}$ alloy sample, most of the coarse grains are in flake-shaped with an average grain size of about $1 \mu \mathrm{m}$. It is also noticed that there is a small portion of fine grains (around $100 \mathrm{~nm}$ ). This means that the microstructure of $\mathrm{Al}$ alloy sample is not uniform, which could be caused by the insufficient deformation during ball milling. The microstructure of the Al-GNSs composite presented in Fig. 9 (c) shows that the addition of 1 vol.\% GNSs dramatically reduce the grain size and the size of the grains is quite similar (app.
$100 \mathrm{~nm}$ ). The grain refinement is firstly attributed to the intensified deformation during ball milling, which greatly reduces the grain size and gets the GNSs well dispersed. Highly deformed regions are marked in Fig. 9(b), where also feature the concentrated sites of dislocations. Secondly, the incorporation of the thin GNSs largely decreases the interplanar distance between GNSs, which could perform pinning effect and restrain the grain growth during hot pressing. It is challenging to directly observe the GNS in the bulk sample using TEM due to the ultrathin profile of the GNSs and the interference from the matrix. Raman spectroscopy is sensitive to carbonaceous materials and offers a reliable tool to

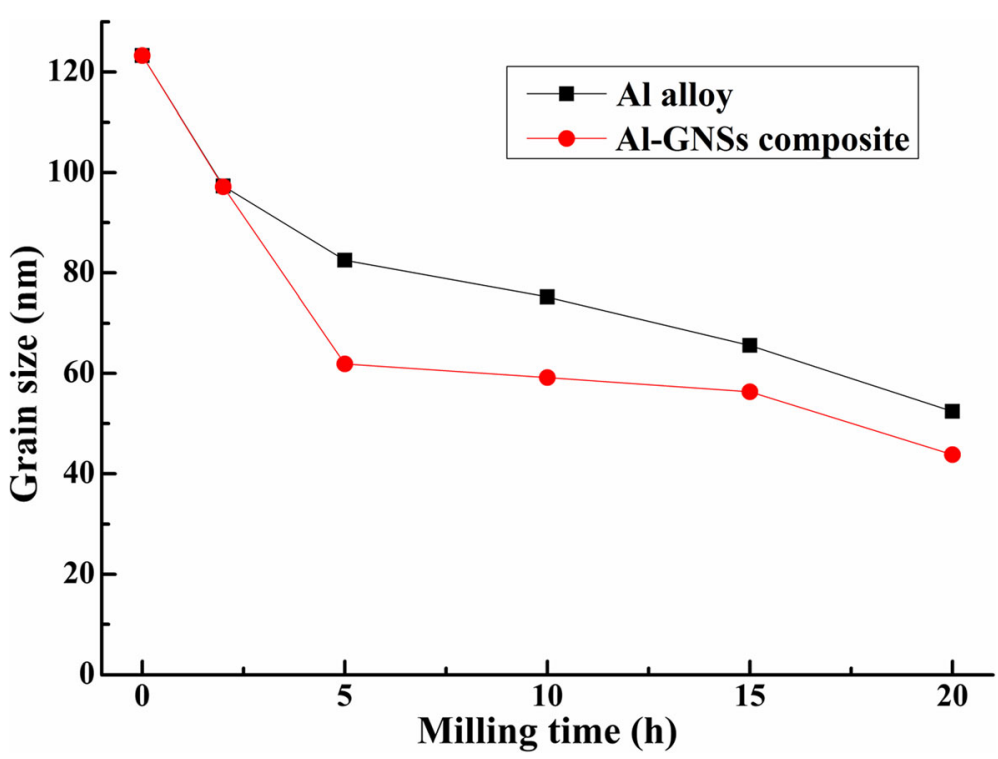

Fig. 7 The evolution of crystalline size for Al alloy and Al-GNSs powder mixtures at different milling times 


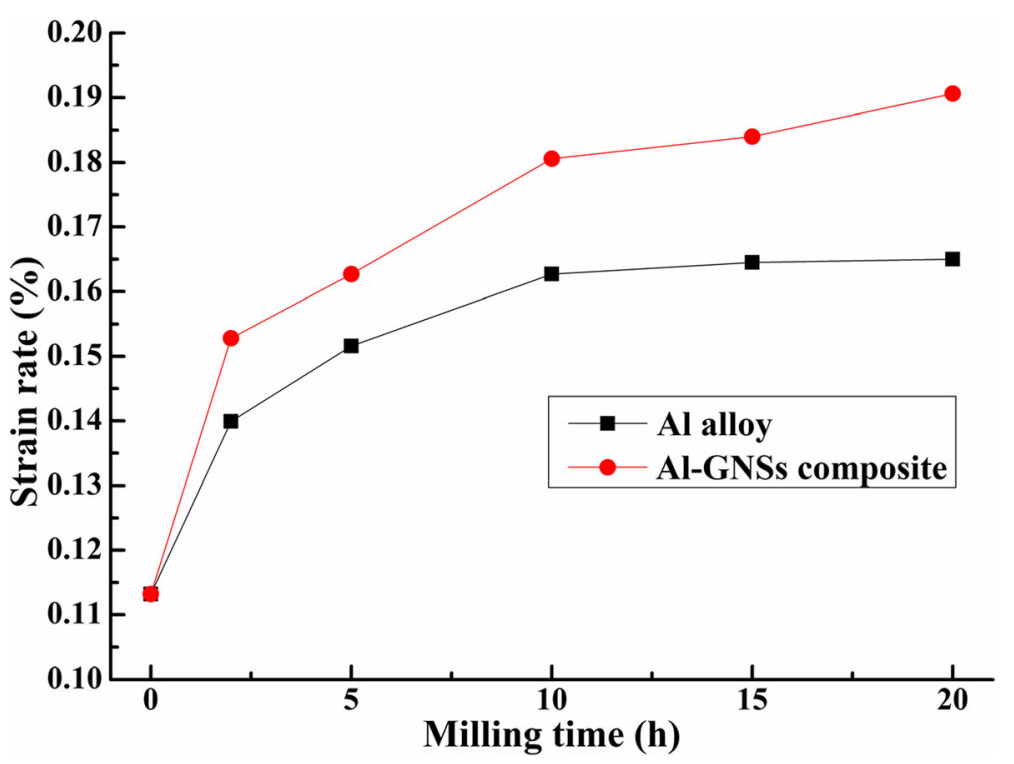

Fig. 8 The evolution of lattice strain for Al alloy and Al-GNSs powder mixtures at different milling times
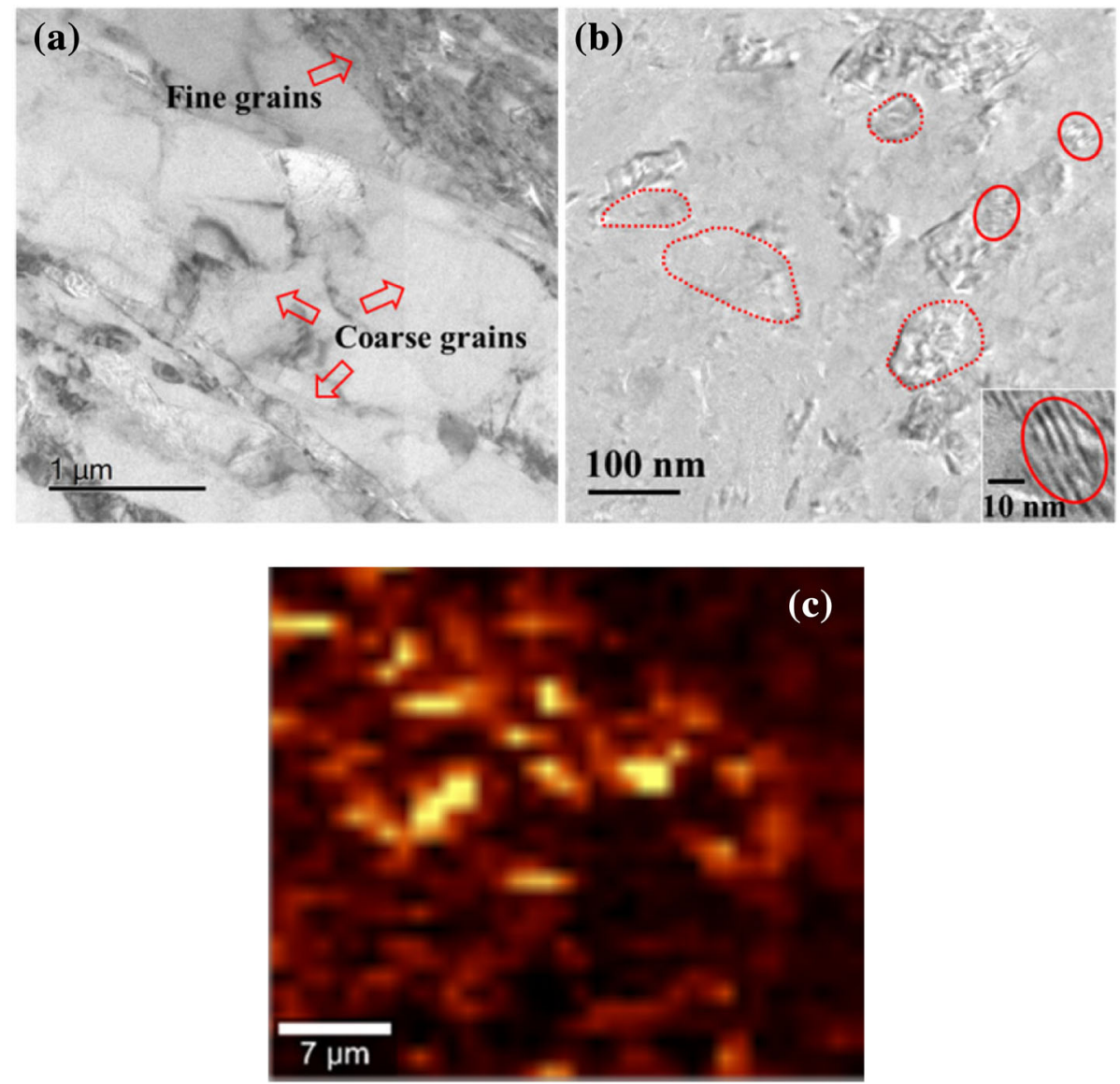

Fig. 9 TEM micrographs of the produced (a) Al alloy, and (b) Al-GNSs composite. Grains are indicated using dashed circles; highly deformed regions are marked using solid circles. c The Raman mapping of $\mathrm{G}$ band on the Al-GNSs composite 
probe the GNSs (Ferrari and Basko 2013). The Raman scanning results of G band are shown in Fig. 9 (c), in which the bright areas represent the presence of GNSs. It is seen that GNSs are well distributed among aluminium matrix.

\section{Hardness}

As shown in Fig. 10, the hardness of the hot-pressed $\mathrm{Al}$ alloy averages at $81.2 \mathrm{HV}$. The hardness of Al-GNSs composite is $115.1 \%$ higher and reaches $174.7 \mathrm{HV}$. This can be understood by considering the presence of GNSs, grain refinement, Orowan strengthening mechanism, the effect of thermal mismatch. The presence of GNSs is difficult to deform and hinders the movement of dislocation (Pérez-Bustamante et al. 2014; Liu et al. 2016). The grain size of the composite is refined and more uniform, which contributes to the increased dislocation and hardness as well. In this regard, Hall-Petch equation was derived to express the relationship between grain size and hardness as follows by combining with Tabor's empirical relationship $H \approx 3 \sigma$. (Petch and Iron Steel 1953; Moon et al. 2008)

$$
H=H_{0}+\Delta H_{\text {Hall-petch }}=H_{0}+3 \times k \cdot d^{-0.5}
$$

where $H$ is the overall hardness, and $H_{0}$ is the hardness of the matrix. $k$ is a modified locking parameter, $0.068 \mathrm{MPa} \cdot \mathrm{m}^{-0.5}$ (Boostani et al. 2015). The $\Delta H_{\text {Hall - petch }}$ is estimated to be $65.8 \mathrm{HV}$ by taking the grain size as $100 \mathrm{~nm}$ for the composite.

The matrix hardness can be further contributed by other mechanisms, as expressed in Eq. (3):

$$
H_{0}=H_{0}^{*}+\Delta H_{\text {Orowan }}+\Delta H_{\mathrm{CTE}}+\Delta H_{L}
$$

where $H_{0}^{*}$ is the intrinsic hardness of the matrix.
$\Delta H_{\text {Orowan }}, \Delta H_{\mathrm{CTE}}$, and $\Delta H_{L}$ represent the contribution from the Orowan strengthening, thermal mismatch mechanism and load-bearing effect, respectively.

The contribution of the dislocation and the impenetrable GNSs to hardness can be explained using Orowan strengthening mechanism as follows (Moon et al. 2008):

$$
\Delta H_{\text {Orowan }}=3 \sqrt{ } 3 \frac{G b}{\lambda}
$$

where $G$ and $b$ represent the shear modulus of the aluminium matrix (26.2 GPa (Khodabakhshi et al. 2017)) and Burgers vector (0.286 nm (Khodabakhshi et al. 2017)) respectively; and $\lambda$ is the interparticle spacing between the dispersoids (taken as $100 \mathrm{~nm}$ ). The $\Delta H_{\text {Orowan }}$ is calculated to be $39.7 \mathrm{HV}$.

Another contributing mechanism is from the thermal mismatch between the GNSs $\left(1 \times 10^{-6} / \mathrm{K}\right)$ and the aluminium matrix $\left(\sim 23.6 \times 10^{-6} / \mathrm{K}\right)$. The hardness increase $\Delta H_{\mathrm{CTE}}$ could be expressed as (Khodabakhshi et al. 2017):

$$
\Delta H_{\mathrm{CTE}}=3 \alpha \mathrm{Gb} \sqrt{\frac{12 \Delta T \Delta C f_{v}}{b d_{p}}}
$$

where $\alpha$ is a proportional constant $(\sim 1.25), \Delta T$ is the temperature difference between the sintering temperature and the ambient temperature ( $475 \mathrm{~K}) . f_{v}$ is the volume fraction of GNSs (1\%). The particle size is selected to be $5 \mu \mathrm{m}$. It is estimated that the contribution from this mechanism is limited and only $2.7 \mathrm{HV}$ is obtained.

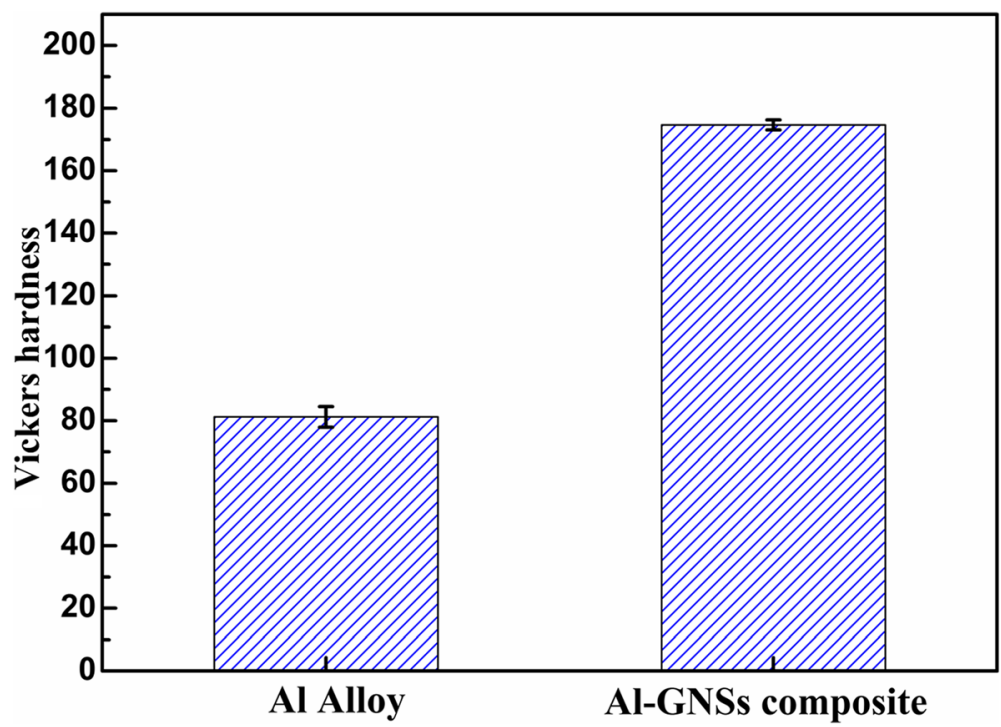

Fig. 10 The mean Vickers hardness of the synthesized Al alloy and Al-GNSs bulk materials 
The hardness enhancement attributed to load bearing could be estimated using the following Eq. (6) (Khodabakhshi et al. 2017):

$$
\Delta H_{\mathrm{L}}=3 \frac{f_{\nu} \sigma_{m}}{2}
$$

where $\sigma_{m}$ represents the yield strength of the matrix. $\sigma_{m}$ is not measured in this study, but normally falls in the range of $100-300 \mathrm{MPa}$ for the aluminium alloy. The $\Delta H_{\mathrm{L}}$ is estimated to be less than $1 \mathrm{HV}$, which is neglectable.

Therefore, the hardness of the Al-GNSs composite is predicted to be $189.4 \mathrm{HV}$ by taking all these effects into account, which is higher than the measured value of 174.4 HV. This could be owing to the presence of defects (such as pores), agglomeration of GNSs, and simplified expressions in Eqs. (2)-(6).

\section{Conclusions}

1) The ductile aluminium particles are firstly flattened at the initial stage of the ball milling, and then fractured and rewelded into equiaxed particles. The addition of the GNSs accelerates the flattening and fracturing, and a smaller particle size is achieved for the composite powder.

2) The XRD analysis reveals that the crystalline size decreases and the lattice strain increases with the progress of the ball milling.

3) The $I(111) / I(200)$ firstly falls to a minimum value and then recovers to the initial level, indicating the creation and elimination of texture during the ball milling, which is consistent with the SEM observation results.

4) The hardness of Al-GNSs composite is $115.1 \%$ higher than that of $\mathrm{Al}$ alloy, which is mainly attributed to the presence of hard GNSs, grain refinement and Orowan strengthening.

\section{Abbreviations}

AMC: Aluminium matrix composite; GNSs: Graphene nanosheets; HV: Vickers hardness; SEM: Scanning Electron Microscope; TEM: Transmission Electron Microscope; XRD: X-ray diffraction

\section{Acknowledgements}

The authors acknowledge use of the facilities at the UOW Electron Microscopy Centre. We appreciate Dr. Monika Wyszomirska who performed the TEM sample preparation and helped interpret the observed results.

\section{Funding}

This study is supported by National Natural Science Foundation of China (NO. 51671100 and 51474127).

\section{Availability of data and materials}

The data and materials are available from the corresponding author.

\section{Authors' contributions}

J Zhang carried out most of the experiments and wrote the manuscript. ZC, J Zhao and ZJ fixed this topic and helped on experimental design, discussion and manuscript revision. All authors read and approved the final manuscript.

\section{Competing interests}

The authors declare that they have no competing interests.

\section{Publisher's Note}

Springer Nature remains neutral with regard to jurisdictional claims in published maps and institutional affiliations.

Received: 21 April 2018 Accepted: 27 August 2018

Published online: 06 September 2018

\section{References}

Alizadeh A, Taheri-Nassaj E, Baharvandi HR (2011) Preparation and investigation of Al-4 wt \% B4C nanocomposite powders using mechanical milling. Bull Mater Sci 34(5):1039-1048

Asgharzadeh H, Sedigh M (2017) Synthesis and mechanical properties of Al matrix composites reinforced with few-layer graphene and graphene oxide. J Alloys Compd 728:47-62

Bartolucci SF, Paras J, Rafiee MA, Rafiee J, Lee S, Kapoor D, Koratkar N (2011) Graphenealuminum nanocomposites. Mater. Sci. Eng. A-Struct. 528(27):7933-7937

Bodunrin MO, Alaneme KK, Chown LH (2015) Aluminium matrix hybrid composites: a review of reinforcement philosophies; mechanical, corrosion and tribological characteristics. J Mater Res Technol 4(4):434-445

Boostani AF, Yazdani S, Mousavian RT, Tahamtan S, Khosroshahi RA, Wei D, Brabazon D, Xu J, Zhang X, Jiang Z (2015) Strengthening mechanisms of graphene sheets in aluminium matrix nanocomposites. Mater Design 88:983-989

El-Ghazaly A, Anis G, Salem HG (2017) Effect of graphene addition on the mechanical and tribological behavior of nanostructured AA2124 selflubricating metal matrix composite. Compos Part A-A 95:325-336

Ferrari AC, Basko DM (2013) Raman spectroscopy as a versatile tool for studying the properties of graphene. Nat Nanotechnol 8(4):235-246

Hu Z, Tong G, Lin D, Chen C, Guo H, Xu J, Zhou L (2016) Graphene-reinforced metal matrix nanocomposites - a review. Mater Sci Technol:1-24

Khodabakhshi F, Arab SM, Švec P, Gerlich AP (2017) Fabrication of a new Almg/graphene nanocomposite by multi-pass friction-stir processing: dispersion, microstructure, stability, and strengthening. Mater Charact 132(Supplement C):92-107

Liu J, Khan U, Coleman J, Fernandez B, Rodriguez P, Naher S, Brabazon D (2016) Graphene oxide and graphene nanosheet reinforced aluminium matrix composites: powder synthesis and prepared composite characteristics. Mater Design 94:87-94

Mazahery A, Shabani MO (2012) Tribological behaviour of semisolid-semisolid compocast Al-Si matrix composites reinforced with TiB2 coated B4C particulates. Ceram Int 38(3):1887-1895

Moon J, Kim S, Jang J-i, Lee J, Lee C (2008) Orowan strengthening effect on the nanoindentation hardness of the ferrite matrix in microalloyed steels. Mater Sci Eng A-Struct 487(1):552-557

Nieto A, Bisht A, Lahiri D, Zhang C, Agarwal A (2016) Graphene reinforced metal and ceramic matrix composites: a review. Int Mater Rev:1-62

Niteesh Kumar SJ, Keshavamurthy R, Haseebuddin MR, Koppad PG (2017) Mechanical properties of Aluminium-Graphene composite synthesized by powder metallurgy and hot extrusion. Trans Indian Inst Metals 70(3):605-613

Novoselov KS, Fal V, Colombo L, Gellert P, Schwab M, Kim K (2012) A roadmap for graphene. Nature 490(7419):192-200

Pérez-Bustamante R, Bolaños-Morales D, Bonilla-Martínez J, Estrada-Guel I, Martínez-Sánchez R (2014) Microstructural and hardness behavior of graphene-nanoplatelets/aluminum composites synthesized by mechanical alloying. J Alloys Compd 615:S578-S582

Petch NJ, Iron Steel IJ (1953) London 173:25

Razavi-Tousi SS, Szpunar JA (2015) Effect of ball size on steady state of aluminum powder and efficiency of impacts during milling. Powder Technol 284:149-158

Shin SE, Choi HJ, Shin JH, Bae DH (2015) Strengthening behavior of few-layered graphene/aluminum composites. Carbon 82:143-151

Stankovich S, Dikin DA, Dommett GHB, Kohlhaas KM, Zimney EJ, Stach EA, Piner RD, Nguyen ST, Ruoff RS (2006) Graphene-based composite materials. Nature 442(7100):282-286

Suryanarayana C, Al-Aqeeli N (2013) Mechanically alloyed nanocomposites. Prog Mater Sci 58(4):383-502

A. Wagih, Mechanical properties of Al-mg/Al2O3 nanocomposite powder produced by mechanical alloying, advanced powder technology (0) (2014)

Zhu Y, Murali S, Cai W, Li X, Suk JW, Potts JR, Ruoff RS (2010) Graphene and Graphene oxide: synthesis, properties, and applications. Adv Mater 22(35):3906-3924 